\title{
Decreased mean platelet volume predicts poor prognosis in patients with pancreatic cancer
}

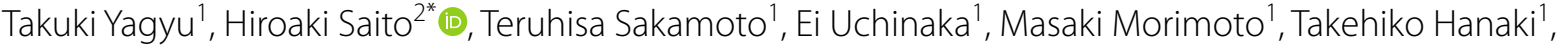 \\ Joji Watanabe' , Tomoyuki Matsunaga', Manabu Yamamoto' ${ }^{1}$, Naruo Tokuyasu' ${ }^{1}$ Soichiro Honjo \\ and Yoshiyuki Fujiwara' ${ }^{1}$
}

\begin{abstract}
Background: Decreased mean platelet volume (MPV) predicts poor prognosis in some cancers. However, its significance as a prognostic indicator in pancreatic cancer $(P C)$ remains unclear.

Methods: A total of 91 PC patients who underwent pancreatectomy were included in this study. MPV and serum carbohydrate antigen 19-9 (CA19-9) were measured within 1 week before surgery.

Results: We divided patients into MPV high $(\geq 8.65 ; n=40), M^{\text {MPV }}(<8.65 ; n=51), C A 19-9^{\text {high }}(\geq 66.3 ; n=47)$, and CA19-9 ${ }^{\text {low }}(<66.3 ; n=44)$ groups based on the optimal cut-off values determined from receiver operating characteristic curve analysis. The 5-year overall survival (OS) rates were significantly lower in the MPVlow than in the MPVhigh group (16.9\% and $56.3 \%$, respectively; $P=0.0038$ ), and the 5 -year disease-specific survival (DSS) rates in the MPVlow group and MPVhigh group were $20.5 \%$ and $62.2 \%$, respectively $(P=0.0031)$. Multivariate analysis identified MPV as an independent prognostic indicator for both OS and DSS. The patients were then divided into groups A (MPVhigh and CA19-9 $\left.9^{\text {low }}\right), B$ (MPVhigh and CA19-9 high), C (MPVlow and CA19-9low), and D (MPVlow and CA19-9 ${ }^{\text {high }}$ ), with 5-year OS rates of $73.2 \%, 40.4 \%, 25.8 \%$, and $10.3 \%$, respectively $(P=0.0002)$, and 5 -year DSS rates of $80.8 \%, 44.9 \%, 27.3 \%$, and $16.4 \%$, respectively $(P=0.0003)$.
\end{abstract}

Conclusions: Classification based on MPV and CA19-9 might be useful for predicting long-term outcomes in patients with PC.

Keywords: Carbohydrate antigen 19-9, Mean platelet volume, Pancreatic cancer, Prognosis

\section{Background}

Predicting the prognosis of cancer patients is important for determining treatment strategies and enabling informed consent to be obtained from patients and their families for treatment of various cancer types. Many prognostic indicators have been identified to date; however, the application of these indicators is difficult

\footnotetext{
${ }^{*}$ Correspondence: sai10@tottori-med.jrc.or.jp

2 Department of Surgery, Japanese Red Cross Tottori Hospital, 117

Shotoku-cho, Tottori 680-8517, Japan

Full list of author information is available at the end of the article
}

because of the expense and complexity of their measurements in routine clinical settings. There is thus a need to identify less invasive and more convenient prognostic indicators. Data obtained from routine blood examinations meets these criteria. A complete blood count (CBC) is an easy and convenient blood test that can be performed in most clinics. The neutrophil to lymphocyte ratio is an indicator that can be evaluated from CBC data, and which is known as a useful prognostic indicator in some cancers $[1,2]$.

Platelets play a pivotal role in cancer metastasis and progression [3]. Because platelet-related 
parameters can be obtained from a $\mathrm{CBC}$, their usefulness as prognostic indicators has been determined in cancer patients, and a close correlation between an increase in peripheral platelets and a poor prognosis has been reported in various cancer types [4-6]. Mean platelet volume (MPV) is a commonly used index of platelet size that has recently attracted attention as a novel prognostic indicator. Indeed, some studies have reported that decreased MPV predicted a poor prognosis in patients with invasive bladder cancer [7] and nonsmall-cell lung cancer $[8,9]$.

Pancreatic cancer (PC) is one of the most aggressive tumors with a 5-year overall survival (OS) rate of less than $5 \%$ worldwide $[10,11]$. The clinical usage of carbohydrate antigen 19-9 (CA19-9) as a marker in PC patients is recommended by the National Comprehensive Cancer Network guidelines. However, approximately $10 \%$ of Japanese patients have a Lewis blood group-negative phenotype and show false-negative findings [12, 13], indicating that CA19-9 alone is not enough to precisely predict the prognosis of $\mathrm{PC}$ patients. Other serum markers are therefore required to predict the prognosis of $\mathrm{PC}$ patients more precisely than using CA19-9 alone. We conducted this study to assess the prognostic value of MPV in patients with PC.

\section{Methods}

This study included 91 patients with pancreatic ductal adenocarcinoma who underwent pancreatoduodenectomy, distal pancreatomy, or total pancreatomy at our institution between January 2008 and December 2017. The eighth edition of the Union for International Cancer Control (UICC) Tumor, Node, Metastasis (TNM) staging system was used to determine the patients' clinicopathological characteristics [14]. The seventh edition of the General Rules for the Study of Pancreatic Cancer by the Japan Pancreas Society was used to evaluate lymphatic invasion, venous invasion, and perineural invasion [15].

Thirteen patients $(14.3 \%)$ were treated with neoadjuvant chemotherapy (gemcitabine and $S-1, n=10 ; S-1$, $\mathrm{n}=2$; gemcitabine and Nab-paclitaxel, $\mathrm{n}=1$ ) and 52 patients $(57.1 \%)$ were treated with postoperative adjuvant chemotherapy ( $\mathrm{S}-1, \mathrm{n}=39$; gemcitabine, $\mathrm{n}=13$ ). The patients visited our outpatient clinic periodically and underwent blood tests and diagnostic imaging, including computed tomography and magnetic resonance imaging.

Preoperative data including serum CA19-9 level, total platelet count, MPV, and platelet distribution width (PDW) were measured within 1 week before surgery.

This study was approved by Certified Review Board, Tottori University Hospital and the requirement for informed consent was waived.

\section{Statistical analyses}

Clinicopathological characteristics were compared using $X^{2}$ tests and the correlation between MPV and serum CA19-9 level was determined by Spearman's rank correlation coefficient. Receiver operating characteristic (ROC) curve analysis was used to determine the Youden index and area under the curve (AUC). Survival curves were generated according to the Kaplan-Meier method and differences were examined using log-rank tests. Multivariate analyses were performed using Cox's proportional hazards model. $P<0.05$ was considered significant. Statistical analyses were carried out using Stat View (Abacus Concepts, Inc., Berkeley, CA, USA) and GraphPad Prism (GraphPad Software, Inc., La Jolla, CA, USA) software.

\section{Results}

We first compared the AUC values of the ROC curves for platelet-related indicators (platelet count, MPV, PDW) and CA19-9 in relation to OS. The AUC was highest for MPV among the four indicators (Fig. 1), indicating that MPV was the most useful prognostic indicator. Patients were then divided into MPVhigh $(\geq 8.65 ; \mathrm{n}=40)$ and $\mathrm{MPV}^{\text {low }}(<8.65 ; \mathrm{n}=51)$ groups based on the optimal cut-off value from ROC curve analysis. Regarding the correlations between MPV and clinicopathological characteristics, the frequency of ly $2 / 3$ was significantly higher in patients with $\mathrm{MPV}^{\text {low }}$ than in those with $\mathrm{MPV}^{\text {high }}$ $(P=0.005)$, while the frequency of $\mathrm{v} 2 / 3$ was significantly
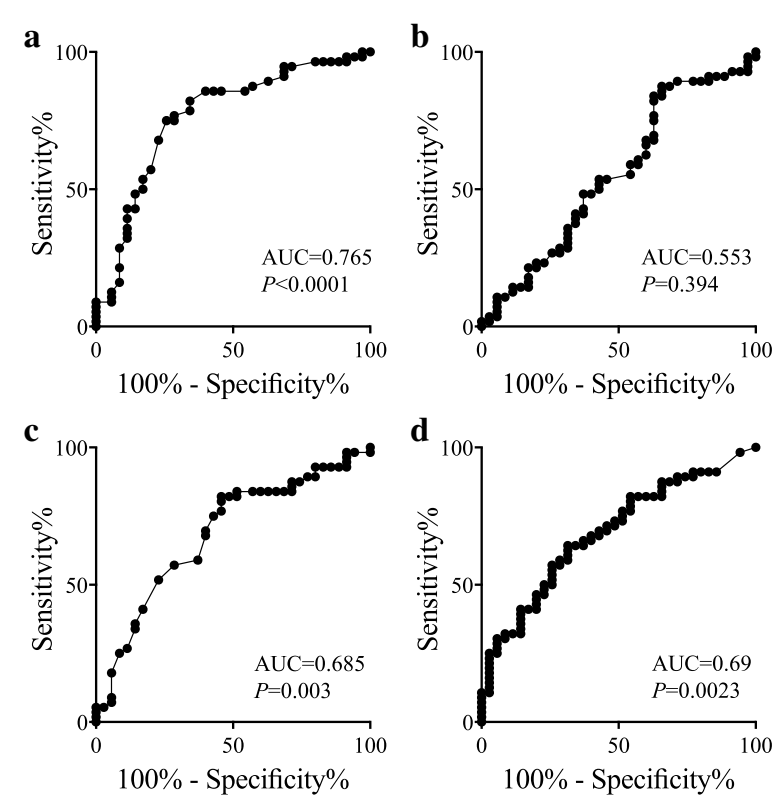

Fig. 1 Receiver operating characteristic curves for overall survival. a MPV, b platelet count, $\mathbf{c}$ PDW, and $\mathbf{d}$ CA19-9 
Table 1 Correlations between the mean platelet volume (MPV) and patients' clinicopathological characteristics

\begin{tabular}{|c|c|c|c|}
\hline & MPV High $^{\text {Hin }=40) ~ n ~(\%) ~}$ & MPVLw $^{\text {Low }}(n=51) n(\%)$ & $P$ value \\
\hline \multicolumn{4}{|l|}{ Age } \\
\hline$<75$ Years & $21(52.5 \%)$ & $32(62.7 \%)$ & 0.39 \\
\hline$\geq 75$ Years & $19(47.5 \%)$ & $19(37.3 \%)$ & \\
\hline \multicolumn{4}{|l|}{ Sex } \\
\hline Male & $22(55.5 \%)$ & $35(68.6 \%)$ & 0.20 \\
\hline Female & $18(44.5 \%)$ & $16(31.4 \%)$ & \\
\hline \multicolumn{4}{|l|}{ Anti-platelet therapy } \\
\hline Absent & $35(87.5 \%)$ & $43(84.3 \%)$ & 0.77 \\
\hline Present & $5(12.5 \%)$ & $8(15.7 \%)$ & \\
\hline \multicolumn{4}{|l|}{ Tumor size } \\
\hline Small $(<3 \mathrm{~cm})$ & $24(60.0 \%)$ & $31(60.8 \%)$ & 0.94 \\
\hline Large $(\geq 3 \mathrm{~cm})$ & $16(40.0 \%)$ & $20(39.2 \%)$ & \\
\hline \multicolumn{4}{|l|}{ Tumor location } \\
\hline Head & $24(60.0 \%)$ & $32(62.7 \%)$ & 0.90 \\
\hline Body/Tail & $16(40.0 \%)$ & $19(37.3 \%)$ & \\
\hline \multicolumn{4}{|l|}{ Histology ${ }^{a}$} \\
\hline wel & $23(57.5 \%)$ & $24(47.1 \%)$ & 0.40 \\
\hline Mod/por / muc/ anaplastic & $17(42.5 \%)$ & 27 (52.9\%) & \\
\hline \multicolumn{4}{|l|}{ T category ${ }^{\mathrm{b}}$} \\
\hline $\mathrm{T} 1 / \mathrm{T} 2$ & $3(7.5 \%)$ & $4(7.8 \%)$ & 0.95 \\
\hline T3 & $37(92.5 \%)$ & $47(92.2 \%)$ & \\
\hline \multicolumn{4}{|l|}{ Lymph node metastasis } \\
\hline Absent & $20(50.0 \%)$ & $17(33.3 \%)$ & 0.13 \\
\hline Present & $20(50.0 \%)$ & $34(66.7 \%)$ & \\
\hline \multicolumn{4}{|l|}{ Lymphatic invasion ${ }^{c}$} \\
\hline ly $0 / 1$ & $30(75.0 \%)$ & $23(45.1 \%)$ & 0.005 \\
\hline ly $2 / 3$ & $10(25.0 \%)$ & $28(54.9 \%)$ & \\
\hline \multicolumn{4}{|l|}{ Vascular invasion $^{d}$} \\
\hline$\vee 0 / 1$ & $14(35.0 \%)$ & $32(62.7 \%)$ & 0.011 \\
\hline$\vee 2 / 3$ & $26(65.0 \%)$ & $19(37.3 \%)$ & \\
\hline \multicolumn{4}{|l|}{ Intrapancreatic nerve invasion ${ }^{\mathrm{e}}$} \\
\hline ne $0 / 1$ & $10(25.0 \%)$ & $11(21.6 \%)$ & 0.80 \\
\hline ne $2 / 3$ & $30(75.0 \%)$ & $40(78.4 \%)$ & \\
\hline \multicolumn{4}{|l|}{ Surgical procedure } \\
\hline PD & $24(60.0 \%)$ & $34(66.7 \%)$ & 0.52 \\
\hline $\mathrm{DP} / \mathrm{TP}$ & $16(40.0 \%)$ & $17(33.3 \%)$ & \\
\hline \multicolumn{4}{|l|}{ Residual tumor } \\
\hline RO & $36(90.0 \%)$ & $47(92.2 \%)$ & 0.73 \\
\hline $\mathrm{R} 1$ & $4(10.0 \%)$ & $4(7.8 \%)$ & \\
\hline \multicolumn{4}{|l|}{ Neoadjuvant chemotherapy } \\
\hline Absent & $35(87.5 \%)$ & $43(84.3 \%)$ & 0.77 \\
\hline Present & $5(12.5 \%)$ & $8(15.7 \%)$ & \\
\hline \multicolumn{4}{|l|}{ Adjuvant chemotherapy } \\
\hline Absent & $18(45.0 \%)$ & $21(41.2 \%)$ & 0.83 \\
\hline Present & $22(55.0 \%)$ & $30(58.8 \%)$ & \\
\hline
\end{tabular}

$P D$ pancreatoduodenectomy, $D P$ distal pancreatectomy, $T P$ total pancreatectomy, $R O$ no residual tumor, $R 1$ microscopic residual tumor

a Histology: wel, well differentiated type; mod, moderately differentiated type; por, tpoorly differentiated type; muc, mucinous carcinoma; anaplastic, anaplastic carcinoma

b T category: $\mathrm{T} 1$, tumor limited to the pancreas, $\leq 20 \mathrm{~mm}$ in the greatest dimension; $\mathrm{T} 2$, tumor limited to the pancreas, $>20 \mathrm{~mm}$ in greatest dimension; $\mathrm{T} 3$, tumor extends beyond the pancreas, but without involvement of the celiac artery or superior mesenteric artery

c ly 0-3: grade of lymphatic invasion

d v 0-3: grade of venous invasion

e ne 0-3: grade of perineural invasion 
$\mathbf{a}$

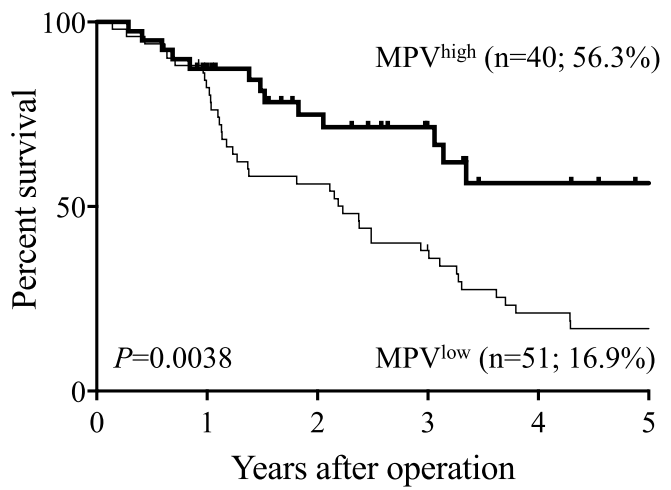

b

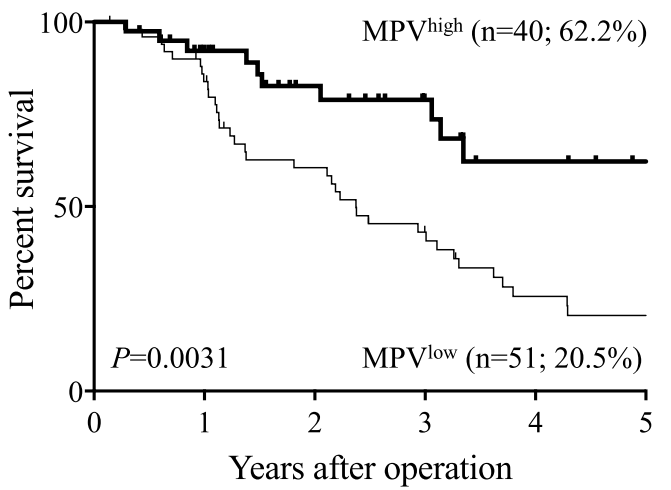

Fig. 2 Survival curves according to MPV. a Overall survival. b Disease-specific survival

Table 2 Multivariate analyses of clinicopathological factors of patients with pancreatic cancer

\begin{tabular}{|c|c|c|c|c|c|c|c|}
\hline & & \multicolumn{3}{|c|}{ Overall survival } & \multicolumn{3}{|c|}{ Disease specific survival } \\
\hline & & HR & $95 \% \mathrm{Cl}$ & $P$ value & HR & $95 \% \mathrm{Cl}$ & $P$ value \\
\hline Age & $\geq 75$ vs. $<75$ Years & 1.518 & $0.665-3.466$ & 0.32 & 1.607 & $0.646-3.996$ & 0.31 \\
\hline Sex & Male vs. female & 0.653 & $0.301-1.413$ & 0.28 & 0.682 & $0.294-1.583$ & 0.37 \\
\hline Histology & Well vs. others & 0.890 & $0.500-1.584$ & 0.69 & 0.876 & $0.465-1.649$ & 0.68 \\
\hline Tumor location & Head vs. others & 1.089 & $0.096-12.423$ & 0.95 & 1.784 & $0.145-21.936$ & 0.65 \\
\hline Operative procedure & PD vs. DP/TP & 1.419 & $0.136-14.841$ & 0.77 & 1.263 & $0.112-14.267$ & 0.85 \\
\hline Tumor size & $\geq 3 \mathrm{~cm}$ vs. $<3 \mathrm{~cm}$ & 1.741 & $0.885-3.426$ & 0.11 & 1.947 & $0.928-4.084$ & 0.078 \\
\hline T category & T3 vs. T1/2 & 1.385 & $0.406-4.170$ & 0.56 & 0.902 & $0.288-2.824$ & 0.86 \\
\hline Lymph node metastasis & Present vs. absent & 3.261 & $1.492-7.127$ & 0.003 & 2.721 & $1.173-6.308$ & 0.020 \\
\hline Lymphatic invasion & ly2/3 vs. ly0/1 & 1.975 & $1.009-3.868$ & 0.047 & 1.749 & $0.837-3.651$ & 0.14 \\
\hline Vascular invasion & v2/3 vs. v0/1 & 1.913 & $0.930-3.934$ & 0.078 & 2.796 & $1.253-6.308$ & 0.012 \\
\hline Intrapancreatic nerve invasion & ne2/3 vs. ne0/1 & 1.506 & $0.700-3.237$ & 0.30 & 1.592 & $0.694-3.650$ & 0.27 \\
\hline Residual tumor & R1 vs. R0 & 5.165 & $1.722-15.493$ & 0.003 & 8.496 & $2.620-27.549$ & $<0.001$ \\
\hline Neoadjuvant chemotherapy & Present vs. absent & 0.559 & $0.230-1.358$ & 0.20 & 0.500 & $0.188-1.331$ & 0.165 \\
\hline Adjuvant chemotherapy & Present vs. absent & 0.346 & $0.153-0.783$ & 0.011 & 0.318 & $0.129-0.783$ & 0.013 \\
\hline CA19-9 & $\geq 66.3$ vs. $<66.3 \mathrm{U} / \mathrm{ml}$ & 2.452 & $1.159-5.187$ & 0.019 & 1.928 & $1.061-4.319$ & 0.044 \\
\hline MPV & $<8.65$ vs. $\geq 8.65 \mathrm{fL}$ & 2.247 & $1.007-5.012$ & 0.048 & 3.578 & $1.411-9.074$ & 0.007 \\
\hline
\end{tabular}

See Table 1 for the details of histology, surgical procedure, T category, lymphatic invasion, vascular invasion, intrapancreatic nerve invasion, and residual tumor Cl confidence interval, HR hazard ratio, CA19-9 carbohydrate antigen 19-9, MPV mean platelet volume

lower in patients with MPV ${ }^{\text {low }}$ than in those with MPV high $(P=0.011)$. Although chemotherapy had the potential to affect MPV, there was no significant relationship between neoadjuvant chemotherapy and MPV $(P=0.77$; Table 1$)$. Furthermore, there was no difference in the usage of antiplatelet drugs between the MPV ${ }^{\text {low }}$ and MPV ${ }^{\text {high }}$ groups $(P=0.77)$.

We then determined the prognostic significance of MPV. The 5-year OS rate was significantly lower in the MPV low $^{\text {compared with the MPV }}{ }^{\text {high }}$ group (16.9\% vs. 56.3\%; $P=0.0038$; Fig. 2a), while the 5-year DSS rates were $20.5 \%$ and $62.2 \%$ in the $\mathrm{MPV}^{\text {low }}$ and MPV high groups, respectively $(P=0.0031$; Fig. $2 \mathrm{~b})$. Multivariate analysis identified MPV as an independent prognostic indicator of OS, together with lymph node metastasis, lymphatic invasion, residual tumor, adjuvant chemotherapy, and CA19-9 (Table 2). Furthermore, MPV was an independent prognostic indicator of DSS, together with lymph node metastasis, vascular invasion, residual tumor, adjuvant chemotherapy, and CA19-9 (Table 2).

We next divided the patients into CA19-9 ${ }^{\text {high }}(\geq 66.3$; $\mathrm{n}=47)$ and CA19-9 ${ }^{\text {low }}(<66.3 ; \mathrm{n}=44)$ groups according to the optimal cut-off value determined by ROC curve analysis. The prognosis of patients in the CA19-9 ${ }^{\text {high }}$ group 

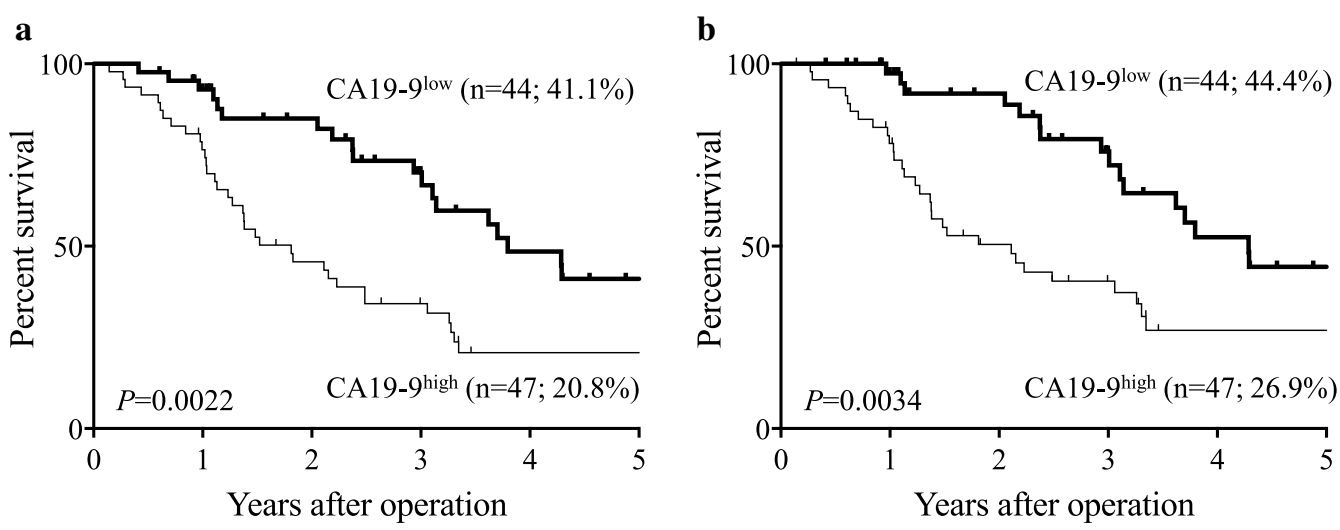

Fig. 3 Survival curves according to serum CA19-9 level. a Overall survival. b Disease-specific survival
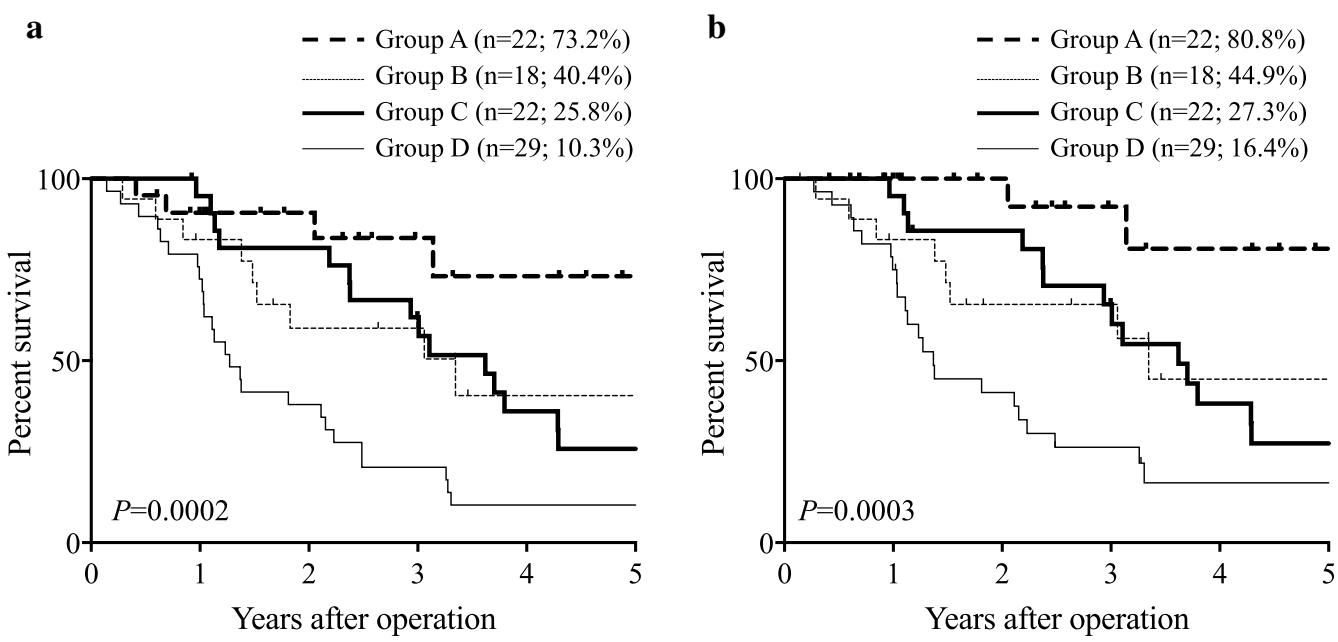

Fig. 4 Survival curves according to the combined analysis of MPV and serum CA19-9 level. a Overall survival. b Disease-specific survival

was significantly poorer than that of the CA19-9 $9^{\text {low }}$ group in terms of both OS (5-year OS rates, $20.8 \%$ vs. $41.1 \%$, respectively; $P=0.0022$; Fig. 3a) and DSS (5-year DSS rates, $26.9 \%$ and $44.4 \%$, respectively; $P=0.0034$; Fig. $3 \mathrm{~b}$ ).

We then determined if the patients' prognosis could be predicted in more detail using MPV combined with CA19-9, as the most common oncological serum marker in PC patients. The relationship between MPV and serum CA19-9 level was not significant $(r=-0.033 ; P=0.755)$, and we therefore divided the patients into groups $\mathrm{A}$ (MPV high and CA19-9 $\left.{ }^{\text {low }}\right)$, B (MPV ${ }^{\text {high }}$ and CA19-9 $\left.{ }^{\text {high }}\right)$, $\mathrm{C}\left(\mathrm{MPV}^{\text {low }}\right.$ and CA19-9 $9^{\text {low }}$ ), and D (MPV low and CA19$\left.9^{\text {high }}\right)$. The 5 -year OS rates in the four groups were $73.2 \%, 40.4 \%, 25.8 \%$, and $10.3 \%$, respectively $(P=0.0002$; Fig. 4a), and the 5 -year DSS rates were $80.8 \%, 44.9 \%$, $27.3 \%$, and $16.4 \%$, respectively ( $P=0.0003$; Fig. $4 \mathrm{~b})$. Finally, groups A, B, C, and D were assigned $0,1,2$, and 3 , respectively. ROC analysis showed that the AUC of the combined analysis of MPV and serum CA19-9 level was higher than that of either MPV or serum CA19-9 level alone for both OS (AUC $=0.815 ; P<0.0001$; Fig. 5a) and DSS (AUC $=0.776 ; P<0.0001 ;$ Fig. 5b).

\section{Discussion}

In this study, we determined the prognostic significance of platelet indices and showed a close relationship between decreased preoperative MPV and poor prognosis in patients with resected PC. Accumulating evidence indicates that platelets play important roles in tumor growth and metastasis. Platelets enhance the penetration of cancer cells through the blood vessel endothelial cell barrier, and prevent their clearance from the circulatory system by the immune cells [16]. Platelets also produce cytokines such as thymidine phosphorylase/ platelet-derived endothelial cell growth factor (PDGF) and transforming growth factor- $\beta 1$ (TGF- $\beta 1$ ). PDGF 

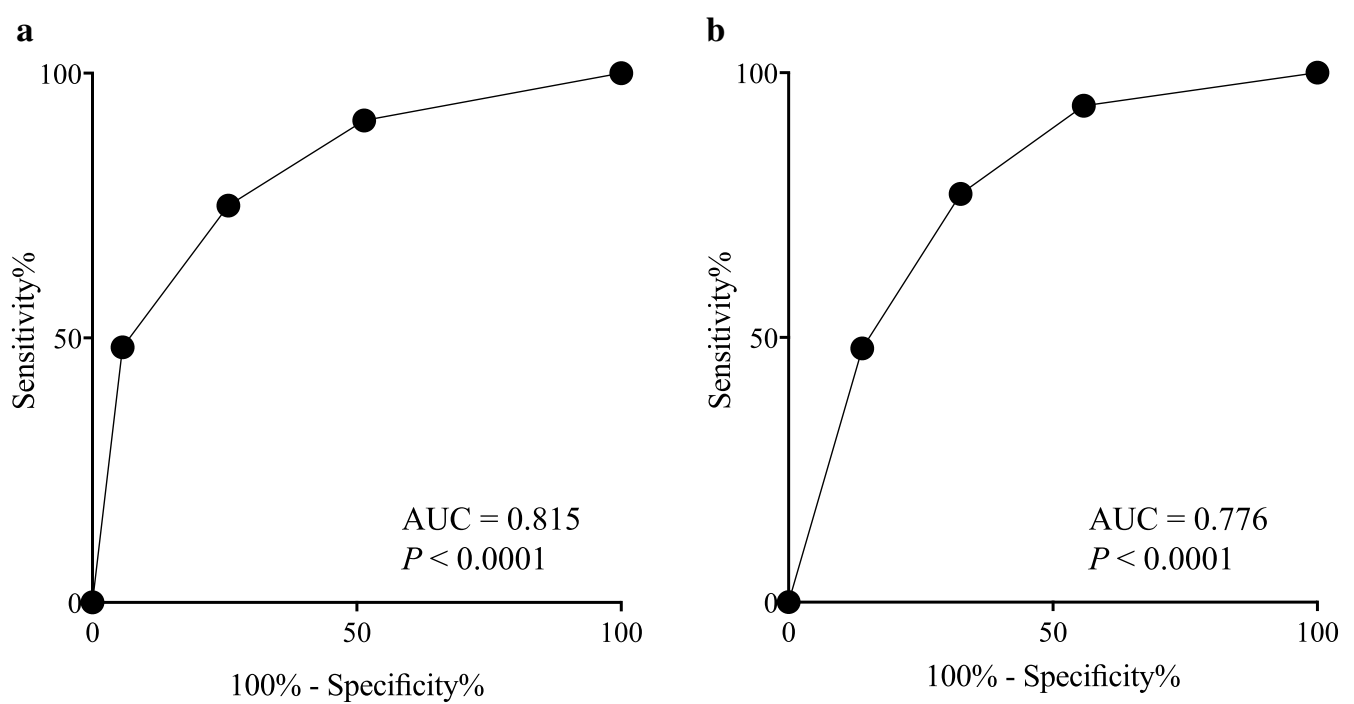

Fig. 5 Receiver operating characteristic curves of the combined analysis of MPV and serum CA19-9 level. a Overall survival. b Disease-specific survival

is a well-described angiogenic factor capable of inducing microvessels at tumor sites, which is closely related to tumor growth and metastasis. Furthermore, mutant p53-induced upregulation of PDGF receptor beta drives invasion and metastasis in PC [17]. PDGF also inhibited the cell-killing effects of natural killer cells [18]. TGF- $\beta 1$ is an immunosuppressive cytokine and also an angiogenic factor. Moreover, direct platelet-tumor cell contacts and platelet-derived TGF- $\beta 1$ synergize to promote an epithelial-mesenchymal transition-like phenotype in vivo, which was found to enhance the migration and invasion of cancer cells [19]. These observations suggest the possible usefulness of platelet indices as a prognostic indicator in cancer patients, including patients with PC.

Thrombocytosis is often observed in cancer patients, given that many types of cancer cells and tumor-infiltrating cells stimulate platelet activation [20, 21]. Furthermore, thrombocytosis is related to a poor prognosis in various cancers [22-24]. However, the prognostic significance of platelet count in the current study was low, indicating the possibility that increased platelet count does not always reflect an increased number of activated platelets. Nonetheless, there was a close correlation between decreased MPV and poor prognosis in this study. Inflammation leads to the accumulation of large platelets at the site of inflammation, resulting in a decreased MPV in the peripheral blood [25]. Furthermore, excessive proinflammatory cytokines interfere with megakaryopoiesis, leading to an increased production of small-sized platelets from the bone marrow [26]. Gasparyan et al. showed that decreased MPV was related to the severity of inflammatory diseases, and that anti-inflammatory therapy increased MPV [27]. These results indicate that decreased MPV reflects the activation of platelets and the spread of inflammation in PC patients. It is likely platelet activation enhances the pro-tumorigenic effects of platelets, which reportedly worsen the prognosis of cancer patients. Because platelets play important roles as inflammatory regulators, their activation also enhances cancer-associated inflammation. Inflammation is closely related to cancer development and progression [28]. Platelet activation and the spread of inflammation might thus explain why a decreased MPV was closely related to poor prognosis in patients with PC. However, the current study did not provide data to directly support these hypotheses, and further investigations are required to clarify the detailed mechanisms responsible for the close relationship between decreased MPV and poor prognosis in PC.

We demonstrated that lymph node metastasis, residual tumor, adjuvant chemotherapy, and serum CA19-9 level were also independent prognostic indicators in this study. These are tumor-related indicators, whereas MPV is a patient-related indicator. Furthermore, our results found no significant correlation between MPV and these tumor markers, indicating the usefulness of MPV as a prognostic indicator regardless of tumor-related prognostic indicators. The difference in origin and lack of a significant correlation between MPV and tumorrelated prognostic indicators encouraged us to determine the prognostic significance of the combination of MPV and tumor-related prognostic indicators. Among 
the tumor-related prognostic indicators, we focused on serum CA19-9, because serum CA19-9 levels can be easily obtained from preoperative blood examination. We demonstrated the prognostic superiority of the combined analysis of MPV and serum CA19-9 level compared with either MPV or serum CA19-9 level alone.

The present study had some limitations. First, its retrospective design was associated with some bias. Second, the number of patients was relatively small, and a larger trial is required to confirm our results. Third, the detailed mechanisms related to the poor prognosis in patients with $\mathrm{MPV}^{\text {low }}$ remain unclear, and further investigations are urgently required to elucidate these.

In conclusion, our study indicated the usefulness of preoperative MPV as a prognostic indicator in patients with resected PC. Because the detection of these serum markers is quick, convenient, and less-invasive, the combined analysis of MPV and serum CA19-9 level could be used as a prognostic indicator for PC patients in the routine clinical setting.

\begin{abstract}
Abbreviations
AUC: Area under curve; CA19-9: Carbohydrate antigen 19-9; CBC: Complete blood count; DSS: Disease-specific survival; MPV: Mean platelet volume; OS: Overall survival; PC: Pancreatic cancer; PDGF: Platelet-derived endothelial cell growth factor; PDW: Platelet distribution width; ROC: Receiver operating characteristic; TGF- $\beta 1$ : Transforming growth factor- $\beta 1$; TNM: Tumor, node, metastasis; UICC: Union for International Cancer Control.
\end{abstract}

\section{Acknowledgements}

We thank H. Nikki March, PhD, and Susan Furness, PhD, from Edanz Group (www.edanzediting.com/ac) for editing drafts of this manuscript.

\section{Authors' contributions}

TY and HS participated in the design of the study, interpretation of data, analysis, and drafting the article. TS, EU, MM, TH, JW, TM, MY, NT, and SH collected data. YF revised the article. All authors read and approved the final version of the article.

\section{Funding}

The authors received no grants, equipment or funding for this study.

\section{Availability of data and materials}

The datasets used and/or analyzed during the current study are available from the corresponding author on reasonable request.

\section{Ethics approval and consent to participate}

All procedures followed were in accordance with the ethical standards of the responsible committee on human experimentation (institutional and national) and with the Helsinki Declaration of 1964 and later versions. This study was approved by Certified Review Board, Tottori University Hospital, and the requirement for informed consent was waived.

\section{Consent for publication}

Not applicable.

\section{Competing interests}

The authors declare that they have no competing interests.

\section{Author details}

${ }^{1}$ Division of Gastrointestinal and Pediatric Surgery, Department of Surgery, School of Medicine, Faculty of Medicine, Tottori University, Tottori, Japan.
2 Department of Surgery, Japanese Red Cross Tottori Hospital, 117 Shotoku-cho, Tottori 680-8517, Japan.

Received: 29 August 2020 Accepted: 19 November 2020

Published online: 06 January 2021

\section{References}

1. Choi WJ, Cleghorn MC, Jiang H, Jackson TD, Okrainec A, Quereshy FA. Preoperative neutrophil-to-lymphocyte ratio is a better prognostic serum biomarker than platelet-to-lymphocyte ratio in patients undergoing resection for nonmetastatic colorectal cancer. Ann Surg Oncol. 2015;22(Suppl 3):S603-613.

2. Matsumoto T, Okabayashi T, Sui K, Morita S, Iwata J, Shimada Y. Preoperative neutrophili-to-lymphocyte ratio is useful for stratifying the prognosis of tumor markers-negative pancreatic cancer patients. Am J Surg. 2020;219(1):93-8.

3. Sharma D, Brummel-Ziedins KE, Bouchard BA, Holmes CE. Platelets in tumor progression: a host factor that offers multiple potential targets in the treatment of cancer. J Cell Physiol. 2014;229(8):1005-15.

4. Suzuki K, Aiura K, Kitagou M, Hoshimoto S, Takahashi S, Ueda M, Kitajima M. Platelets counts closely correlate with the disease-free survival interval of pancreatic cancer patients. Hepatogastroenterology. 2004;51(57):847-53.

5. Long Y, Wang T, Gao Q, Zhou C. Prognostic significance of pretreatment elevated platelet count in patients with colorectal cancer: a metaanalysis. Oncotarget. 2016;7(49):81849-61.

6. Pietrzyk L, Plewa Z, Denisow-Pietrzyk M, Zebrowski R, Torres K. Diagnostic power of blood parameters as screening markers in gastric cancer patients. Asian Pac J Cancer Prevent APJCP. 2016;17(9):4433-7.

7. Wang X, Cui MM, Xu Y, Liu L, Niu Y, Liu T, Liu ZP, Wang RT, Yu KJ. Decreased mean platelet volume predicts poor prognosis in invasive bladder cancer. Oncotarget. 2017;8(40):68115-22.

8. Kumagai S, Tokuno J, Ueda Y, Marumo S, Shoji T, Nishimura T, Fukui M, Huang CL. Prognostic significance of preoperative mean platelet volume in resected non-small-cell lung cancer. Mol Clin Oncol. 2015;3(1):197-201.

9. Inagaki N, Kibata K, Tamaki T, Shimizu T, Nomura S. Prognostic impact of the mean platelet volume/platelet count ratio in terms of survival in advanced non-small cell lung cancer. Lung Cancer (Amsterdam, Netherlands). 2014;83(1):97-101.

10. Torre LA, Bray F, Siegel RL, Ferlay J, Lortet-Tieulent J, Jemal A. Global cancer statistics, 2012. CA Cancer J Clin. 2015;65(2):87-108.

11. Vincent A, Herman J, Schulick R, Hruban RH, Goggins M. Pancreatic cancer. Lancet (London, England). 2011;378(9791):607-20.

12. Ritts RE, Pitt HA. CA 19-9 in pancreatic cancer. Surg Oncol Clin N Am. 1998;7(1):93-101.

13. Goonetilleke KS, Siriwardena AK. Systematic review of carbohydrate antigen (CA 19-9) as a biochemical marker in the diagnosis of pancreatic cancer. Eur J Surg Oncol. 2007;33(3):266-70.

14. Brierley JDGM, Wittekind C. TNM classification of malignant tumours. 8th ed. New Jersey: Wiley-Blackwell; 2017.

15. Japan Pancreas Society. Gerenal rules for the study of pancreatic cancer. 7th ed. Kanehara: Tokyo; 2016.

16. Karpatkin S, Pearlstein E. Role of platelets in tumor cell metastases. Ann Intern Med. 1981:95(5):636-41.

17. Weissmueller S, Manchado E, Saborowski M, Morris JPt, Wagenblast E, Davis CA, Moon SH, Pfister NT, Tschaharganeh DF, Kitzing T, et al. Mutant p53 drives pancreatic cancer metastasis through cell-autonomous PDGF receptor beta signaling. Cell. 2014;157(2):382-94.

18. Peterson JE, Zurakowski D, Italiano JE Jr, Michel LV, Connors S, Oenick M, D'Amato RJ, Klement GL, Folkman J. VEGF, PF4 and PDGF are elevated in platelets of colorectal cancer patients. Angiogenesis. 2012;15(2):265-73.

19. Labelle M, Begum S, Hynes RO. Direct signaling between platelets and cancer cells induces an epithelial-mesenchymal-like transition and promotes metastasis. Cancer Cell. 2011;20(5):576-90.

20. George ML, Eccles SA, Tutton MG, Abulafi AM, Swift RI. Correlation of plasma and serum vascular endothelial growth factor levels with platelet count in colorectal cancer: clinical evidence of platelet scavenging? Clin Cancer Res. 2000;6(8):3147-52. 
21. Gunsilius E, Petzer A, Stockhammer G, Nussbaumer W, Schumacher P, Clausen J, Gastl G. Thrombocytes are the major source for soluble vascular endothelial growth factor in peripheral blood. Oncology. 2000;58(2):169-74.

22. Ikeda M, Furukawa H, Imamura H, Shimizu J, Ishida H, Masutani S, Tatsuta $\mathrm{M}$, Satomi T. Poor prognosis associated with thrombocytosis in patients with gastric cancer. Ann Surg Oncol. 2002;9(3):287-91.

23. Tomita M, Shimizu T, Hara M, Ayabe T, Onitsuka T. Preoperative leukocytosis, anemia and thrombocytosis are associated with poor survival in non-small cell lung cancer. Anticancer Res. 2009;29(7):2687-90.

24. Gorelick C, Andikyan V, Mack M, Lee YC, Abulafia O. Prognostic significance of preoperative thrombocytosis in patients with endometrial carcinoma in an inner-city population. Int J Gynecol Cancer. 2009;19(8):1384-9.

25. Gasparyan AY, Sandoo A, Stavropoulos-Kalinoglou A, Kitas GD. Mean platelet volume in patients with rheumatoid arthritis: the effect of antiTNF-alpha therapy. Rheumatol Int. 2010;30(8):1125-9.
26. Refaai MA, Phipps RP, Spinelli SL, Blumberg N. Platelet transfusions: impact on hemostasis, thrombosis, inflammation and clinical outcomes. Thromb Res. 2011;127(4):287-91.

27. Gasparyan AY, Ayvazyan L, Mikhailidis DP, Kitas GD. Mean platelet volume: a link between thrombosis and inflammation? Curr Pharm Des. 2011;17(1):47-58.

28. Grivennikov SI, Greten FR, Karin M. Immunity, inflammation, and cancer. Cell. 2010;140(6):883-99.

\section{Publisher's Note}

Springer Nature remains neutral with regard to jurisdictional claims in published maps and institutional affiliations.
Ready to submit your research? Choose BMC and benefit from:

- fast, convenient online submission

- thorough peer review by experienced researchers in your field

- rapid publication on acceptance

- support for research data, including large and complex data types

- gold Open Access which fosters wider collaboration and increased citations

- maximum visibility for your research: over $100 \mathrm{M}$ website views per year

At BMC, research is always in progress.

Learn more biomedcentral.com/submissions 